\title{
An Analysis of Audience's Use of Weibo from the Perspective of Uses and Gratifications Theory
}

\author{
Siyu Li
}

\author{
Buffalo seminary, Buffalo, New York, U.S.A., 205 bidwell pkwy, Buffalo seminary, 14222 \\ Email:gfe287772@163.com
}

\begin{abstract}
With the rapid development of the Internet era, traditional media such as radio dramas, newspapers, weekly magazines, etc. have gradually reduced their influence on the public. And new media platforms are flooding in and entering people's field of vision. The development of social media infuses the modern relationships with vitalities and brings a series of information dissemination with subjective consciousness. This is one of the general characteristics of the information age after a widespread wave of Social Network Services(SNS), arousing the unprecedented management pressure for the Chinese government[1].Such as QQ, Douyin, Zhihu, Toutiao and Weibo. These are all very popular media in today's society. Among them, Weibo is even best. Among the web 2.0 applications, a microblog (Weibo in Chinese), resembling the combination of a Twitter-like Internet service has gained substantial popularity in China. Sina Weibo is the market leader with approximately $50 \%$ of the market share. Around $80 \%$ of the users on Sina Weibo are young people. Hence, it is necessary to analyze young Chinese users of Sina Weibo and examine whether Sina Weibo fulfills the needs of young people and whether Sina Weibo meets their expectations [2]. Weibo is suitable for people with different needs. "Uses and Gratifications " theory focuses on the audience's motivation to contact the media and its needs. However, retaining users for an extended period is yet another vital aspect that developers and managers should embrace [3]. Virtual community sustainability depends on users' continuance intention [4]. So in the media age where the needs of audiences are constantly diversified, whether Weibo meets the needs of the audience and how to meet them, and why Weibo stands out among the many new media platforms is of great research significance.
\end{abstract}

Keywords: Uses and Gratifications, New Media, Weibo

\section{INTRODUCTION}

The times are changing rapidly, now is the era of new media. The online world is full of people's lives. Recent estimates suggest there are over 72 million adult Internet users in the U.S. alone (intelliquest 1999)[5]. With the rapid development of new media, the living room culture has gradually faded in people's lives. Participatory, interactive, and open new media forms are becoming more and more popular. All major apps occupy a place in this era[6]. Weibo is a more popular and diversified new media. All kinds of people are using Weibo. The reason why Weibo continues to stand out among popular media is that it has so many functions. Hot search list, entertainment list, super chat, attention, etc. meet the needs of all kinds of people. The various characteristics of Weibo are of research significance. Microblog is one of the most popular online social networking service, which has tremendous growth all over the world in recent years. As the first microblogging site and most influential social media platform, Twitter has been well documented. Nowadays, the number of Internet user in China take the first place in the world, however the popular Chinese microblogging service Sina Weibo has not been studied[7]. Therefore, this paper will analyze the audience's use of microblog from the perspective of use and satisfaction theory.

\section{WEIBO OVERVIEW}

The alias of Weibo is MicroBlog, which is a software that can be used as an audience to browse news or information that interests you, or as a publisher, to publish a video or article content. Weibo can also share your status, mood, dynamics, etc. in fact. Not only that, the entertainment industry is also a big part of Weibo. All kinds of celebrities, actors' dynamics, and 
news will appear on the Weibo hot search list. Not only that, Weibo will also update the world's major news, real-time and so on. A software does not leave home, knowing that you can still get all the information in a foreign country.

The earliest Weibo was actually the US Twitter (Twitter) founded by Evan Williams in March 2006. In August 2009, China officially launched Sina Weibo. With the rapid spread of news, Weibo has had a considerable impact in China and the world.

Weibo is highly grass-rooted and widely distributed on multiple platforms such as desktops, browsers and mobile terminals. Traditional media has a large economic scale and "huge, arrogant organization." The "grassroots media" such as Weibo does not have any "threshold", and anyone with citizenship can join[8].This is also the reason why Weibo is able to take the top spot in all major APPs in addition to its outstanding functions.

\section{MOTIVATION OF WEIBO AUDIENCES}

As a popular media software in my country, Xinlang Weibo has very diverse functions. Including follow, recommendation, likes by people who follow, hot search list (entertainment list, news list, city list), hot topics, frequently visited users, and super chats. So many features are for all kinds of audiences. There are obviously many motivations for the audience to choose to use Weibo. A Web survey of 1,715 college students was conducted to examine Facebook Groups users' gratifications and the relationship between users' gratifications and their political and civic participation offline. A factor analysis revealed four primary needs for participating in groups within Facebook: socializing, entertainment, self-status seeking, and information. These gratifications vary depending on user demographics such as gender, hometown, and year in school[9]. The audience usage of sina Weibo is inspired by it, as follows.

Table 1.Weibo audience motivation statistics

\begin{tabular}{|l|l|l|l|l|}
\hline $\begin{array}{l}\text { Choose } \\
\text { Motivati } \\
\text { on }\end{array}$ & $\begin{array}{l}\text { Entertai } \\
\text { nment } \\
\text { needs }\end{array}$ & $\begin{array}{l}\text { Emotion } \\
\text { al needs }\end{array}$ & $\begin{array}{l}\text { Social } \\
\text { needs }\end{array}$ & $\begin{array}{l}\text { Busines } \\
\text { s needs }\end{array}$ \\
\hline $\begin{array}{l}\text { Overall } \\
\text { number } \\
\text { of } \\
\text { people }\end{array}$ & 25 & 12 & 22 & \\
\hline Gender & $\begin{array}{l}\text { Male:7 } \\
\text { Female: } \\
18\end{array}$ & $\begin{array}{l}\text { Male:3 } \\
\text { Female: } \\
10\end{array}$ & $\begin{array}{l}\text { Male:10 } \\
\text { Female: } \\
12\end{array}$ & \\
\hline Age & $\begin{array}{l}\text { Average } \\
17-25\end{array}$ & $\begin{array}{l}\text { Average } \\
25\end{array}$ & $\begin{array}{l}\text { Average } \\
18\end{array}$ & \\
\hline
\end{tabular}

According to statistics, women generally use Weibo more than they generally use men. The most obvious manifestation is the demand for entertainment. Men usually use Weibo for entertainment to follow sports events and relax. Moreover, women are for the entertainment news and star chasing on the entertainment list. At the same time, the survey age group is generally between middle school and university, and it can be seen that there is no audience for business needs. The most typical example of business needs is to make money by publishing articles on Weibo as a media reporter (marketing account). Nevertheless, most people use Weibo to relax. Therefore, in the survey group, there are no users who use microblog because of business needs. In addition, social needs are also the reason why audiences choose to use Weibo in addition to entertainment needs. According to the survey, men use Weibo to socialize mostly for game discussions, while women use Weibo to follow stars. For example, microblog has the function of "Chaohua". Chaohua is an interest community based on a sustainable discussion topic. It is divided into different areas, such as stars, games and sports events. Men usually study the playing methods or equipment of various games in the game Chaohua, and everyone will form a team according to their own game level. Women usually discuss their favorite stars in the Star Chaohua, study the clothes brands they wear or plays they have made, and talk through observation.

However, both male and female audiences have the need to use Weibo. In addition, the age span is relatively large, which shows that the audience of Weibo is relatively wide.

\section{FEATURED CONTENT OF WEIBO}

Weibo is the Twitter counterpart in China that has attracted hundreds of millions of users. We crawled an almost complete Weibo user network that contains 222 million users and 27 billion links in 2013[10].

As a social media, Sina Weibo has the dual role of connecting users (social) and exchanging information (media). Sina Weibo's transformation from "cottage" to independent innovation, to a gathering place for news reversal, to being given more social responsibilities, and the centralization and decentralization (verticalization) that have emerged in this process, makes Sina Weibo Bo forms its own characteristics. [11] In today's news dissemination methods, Weibo dominates. Whether it is traditional media seeking to change or new media that emerged in response to the times, they use Weibo to publish news, and netizens use an open information platform such as Weibo. To obtain information, Weibo can be said to be one of the main ways for netizens to obtain news[12]. Weibo has established a certain perfect system through continuous improvement since its establishment. First, content that is not conducive to 
the physical and mental health of young people, the Weibo backstage will be blocked as soon as possible. At the same time, the hot search list and entertainment list of Weibo is a big feature of our country's APP. In the hot search list are the major events that have occurred in the country and the world in the past day. Such as disasters and so on. Moreover, the breaking news in the entertainment list will appear in the hot search list. Overall, Weibo's hot search list is for people with various needs and can answer many questions. The third feature of Weibo is Chaohua. Chaohua is a gathering place for star chasers. Make rankings, likes, super chats, etc. for your favorite artists every day. At the same time, you can know the latest news about your favorite artists in Chaohua. These are the three distinctive features of the Weibo function. The concept of "big data" must be a major focus in today's era of rapid development of science and technology and network. Another reason why Sina Weibo continues to attract more users is the "recommendation" function of Weibo. In the era of big data, the recommendation function of microblog will be integrated according to the frequency, time, location, browsing software and search frequency of users using electronic products today, and recommend the content that users may be interested in. This can provide users with more convenience and reduce some time trouble.

Weibo is also a software for publishing personal content. It can be as big as celebrity bloggers posting their own news, bringing goods, checking in, etc., as small as people posting mood, real-time and other content do. Each function can meet the needs of different audiences. The diversification and individualization of Weibo is its biggest feature.

\section{AUDIENCE SATISFACTION}

The audience needs of Weibo are mainly entertainment needs, social needs and emotional needs. Under these needs, audiences with entertainment needs can get the latest information through the hot search lists, entertainment lists and super chats of Weibo. Get information that interests you. At the same time, in the process of ranking, the audience can participate by themselves with a certain degree of interaction. Stars are no longer out of reach. The emotional needs are not only for men and women, but also for the country. Or, for example, in the Tokyo Olympic Games just ended some time ago, the number of gold medals of various countries will be broadcast in real time on the microblog, but there are many busy office workers or students who have no time to pay attention to sports events in real time. But microblogging brings the fastest and most intuitive results. It meets their emotional needs for patriotism. Interactivity is also reflected in the audience with social and emotional needs. Social needs, as the name suggests, is to make friends and other interactions with the help of microblog. Because microblog is an online media, in the social process, the audience can make friends and talk through the Internet without worrying about face-to-face embarrassment. This can alleviate anxiety and meet the needs of the audience. For example, some star chasing girls will discuss their favorite star Aidou together on their microblog. Vote for them together. In this process, they may also share what happened in their real life. May be in different places, different ages, but in the online world, it alleviates everyone's embarrassment.

Another example is a comparative survey of the use and satisfaction of American and Chinese fans on social media platforms. This study of 409 sports fans from the United States and China contrasts uses sought and gratifications obtained within four different social media platforms: Facebook and Twitter (in the United States) and WeChat and Weibo (in China). Results indicated that each of the platforms function in starkly contrasting manners. In the United States, Facebook scored higher than Twitter on every motivational measure; in China, WeChat was found to be better at fostering camaraderie, entertainment, habitual use, and maintaining relationships, while Weibo was found to be better for arousal. Moreover, Chinese respondents reported higher gratifications obtained than American respondent on all 12 factors[13].

The study also found that these motivations were significantly different between male and female users. Interestingly, female respondents used Sina Weibo much more broadly than male counterparts, accessing it to satisfy all needs such as information gathering, accessibility to celebrity, social connection, selfpresentation and entertainment. Based on these findings limitations and direction for future studies are discussed[7].Because it can also be found in the research that male users are limited to a few points in terms of entertainment and social networking. Women's microblog experience has not so many limitations. So this is the main reason for the differences between men and women.

And the other study finds more respondents use Weibo each day than use news websites each day. They spent significantly more time on Weibo than on news websites. Respondents considered Weibo to be significantly more helpful than news websites for obtaining news gratifications[14].

It can be seen that microblog meets a variety of different audiences in life.

\section{CONCLUSION}

Under the theoretical framework of " Uses and Gratifications", this article studies the needs of various functions of Weibo from the perspective of the audience. It can help people understand the applicable 
angles of Weibo, and further understand which features of Weibo need to meet their needs. Finally, we can understand the current situation of the needs of various audiences of the Weibo function under the use and satisfaction.

In general, in the era of the rapid development of the Internet and science and technology, microblog can take the lead among many apps, which is inseparable from its own advantages and functions.

When investigating the motivation of microblog use, the model of questionnaire can get some results more accurately. At the same time, the characteristic content and function of microblog are still improving and developing. Just like recently, Sina Weibo is still updating its version. Constantly adjust according to the needs of users. Only on the basis of continuous improvement can we ensure that the number of users only increases. Because of the rapid development of science and technology in the times.

There are countless social software overseas, and microblog is slightly inferior to it. While Facebook and Twitter get worldwide attention, these popular SNSs are not available in China. As the leading local SNS, Sina Weibo has garnered much of the attention in China.If Sina Weibo wants to develop overseas, it is very important that the automatic translation settings of various languages need to be more sensitive. In order to attract the most basic overseas users. Let Sina Weibo open the world market.

\section{REFERENCES}

[1]Y. Liu and Y. Zhou, "Social media in China: Rising Weibo in government," 5th IEEE International Conference on Digital Ecosystems and Technologies (IEEE DEST 2011), 2011, pp. 213219, doi: 10.1109/DEST.2011.5936628.

[2]Wang, J. Analysis of Young Chinese Users of Sina Weibo Based on Uses and Gratifications Theory (Dissertation). Retrieved from http://urn.kb.se/resolve?urn=urn:nbn:se:hj:diva40864.2018.

[3]Bhattacherjee, A. Understanding information systems continuance: An expectation-confirmation model. MIS Q. 2001, 25, 351-370.

[4]Jin, X.L.; Lee, M.K.; Cheung, C.M. Predicting continuance in online communities: Model development and empirical test. Behav. Inf. Technol. 2010, 29, 383-394.

[5]Parker, Betty J; Plank, Richard E. American Business Review; West Haven Vol. 18, Iss. 2, (Jun 2000): 43-49.
[6]Miao Chen and Yunfeng Wang. Highlighting "Use and Gratifications" : A new idea for the development of TV variety Shows in the Era of Integration of media." China TV.06(2021):81-84. doi:CNKI:SUN:ZGDD.0.2021-08-22.

[7]Shaoyong Chen, Huanming Zhang, Min Lin and Shuanghuan Lv, "Comparison of microblogging service between Sina Weibo and Twitter," Proceedings of 2011 International Conference on Computer Science and Network Technology, 2011, pp. 2259-2263, doi: 10.1109/ICCSNT.2011.6182424.

[8]The "disruptive innovation" of Weibo. People's Daily Online [2021-08-27]

[9]Namsu Park, Kerk F. Kee, and Sebastián Valenzuela.CyberPsychology \& Behavior.Dec 2009.729.

733.http://doi.org/10.1089/cpb.2009.0003

[10]W. Han, X. Zhu, Z. Zhu, W. Chen, W. Zheng and J. Lu, "A comparative analysis on Weibo and Twitter," in Tsinghua Science and Technology, vol. 21, no. 1, pp. 1-16, Feb. 2016, doi: 10.1109/TST.2016.7399279.

[11]Xiang Chen. "Social Media in China: A Case study of Sina Weibo." Communication \& Copyright.05(2020):147-148. doi:10.16852/j.cnki.45-1390/g2.[2021-09-12]

[12]Zi Ye. Research on the Communication content of Sina Sports Microblog.2019. Wuhan Sports University,MA Thesis.[2021-09-15]

[13]Andrew C. Billings, Ryan M. Broussard, Qingru $\mathrm{Xu}$, Mingming XuFirst Published August 2, 2018 Research Article.

[14]Xiong, Si. A Comparative Study of Uses and Gratifications Between Weibo and News Websites in China. 2014. Ohio University, Master's thesis. OhioLINK Electronic Theses and Dissertations Center, http://rave.ohiolink.edu/etdc/view?acc_num=ohiou 1399379495. 